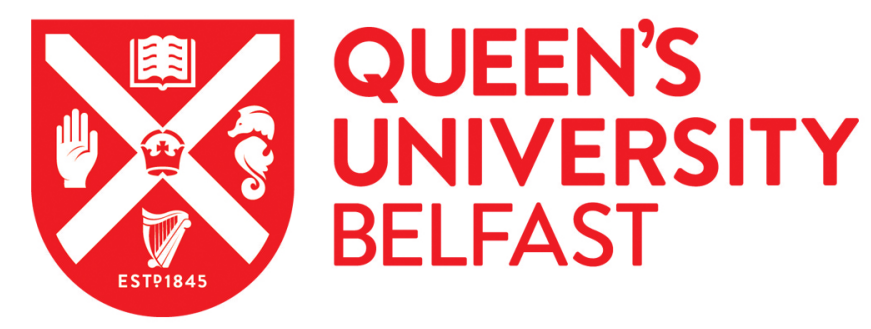

\title{
Toward a Policy Social Psychology: Teacher Engagement with Policy Enactment and the Core Concept of Affective Disruption
}

Bagley, C., \& Shiekh, I. (2018). Toward a Policy Social Psychology: Teacher Engagement with Policy Enactment and the Core Concept of Affective Disruption. British Educational Research Journal, 44(1), 43-60.

https://doi.org/10.1002/berj.3316

Published in:

British Educational Research Journal

Document Version:

Peer reviewed version

Queen's University Belfast - Research Portal:

Link to publication record in Queen's University Belfast Research Portal

Publisher rights

(c) 2017 British Educational Research Association.

This work is made available online in accordance with the publisher's policies. Please refer to any applicable terms of use of the publisher.

\section{General rights}

Copyright for the publications made accessible via the Queen's University Belfast Research Portal is retained by the author(s) and / or other copyright owners and it is a condition of accessing these publications that users recognise and abide by the legal requirements associated with these rights.

Take down policy

The Research Portal is Queen's institutional repository that provides access to Queen's research output. Every effort has been made to ensure that content in the Research Portal does not infringe any person's rights, or applicable UK laws. If you discover content in the Research Portal that you believe breaches copyright or violates any law, please contact openaccess@qub.ac.uk. 


\title{
Toward a Policy Social Psychology: Teacher Engagement with Policy Enactment and the Core Concept of Affective Disruption
}

\begin{abstract}
The article uncovers the complex process of educational policy enactment and the impact this process has on teachers as policy actors as they undertake the task of introducing a new mathematics curriculum in a Canadian secondary school. The three year study based on indepth qualitative interviews adopts a classic grounded theory approach (Glaser and Strauss, 1967) of concurrent iterative cycles of data collection, conceptual categorization and analytical abstraction, to identify six emergent concepts indicative of policy actor engagement with the policy process: (1) Professional and Emotional Investment, (2) Decisional Legitimacy, (3) Hierarchical Trust, (4) System Integrity and Viability, (5) De-professionalization and (6) Identity Safeguarding. Further, and significantly, the grounded theory analysis identifies the core concept of Affective Disruption, conceived as an interruption to an individual's emotional equilibrium resulting from interference to their cognitive sensemaking in relation to policy. It is proposed these six emergent concepts and Affective Disruption as a core concept are precipitated within policy actors in response to the tensions created by the process of policy enactment; the research findings moving toward what might be tentatively termed a policy social psychology.
\end{abstract}

\section{Key Words}


Institutional Context, Political Economic and Cultural Contexts, Grounded Theory, Policy Enactment

\section{Introduction}

The research presented in this paper is concerned with a qualitative uncovering of the ways in which teachers - positioned as policy actors (Ball et al 2012) - engage with a process of policy enactment as conceived by Ball et al (2012):

Policy enactment involves creative processes of interpretation and recontextualisation

that is the translation of texts into action and the abstractions of policy ideas into contextualised practice

(Ball et al 2012, p3)

In line with a number of recent works which have sought to provide a more nuanced engagement with this conceptual work in theoretical terms as well as in different national and site-based contexts (see for example, Maguire et al 2015; Singh et al., 2013, 2014; Tan, 2017; Vincent et al 2016), this paper seeks to engage with the ways is which 'policy enactment is a process of social, cultural and emotional construction and interpretation' (Maguire, 2015, p.7). In particular, the ways in which more social psychologically situated affective dimensions associated with policy enactment, relatively neglected to-date in the extant literature, need to be more deeply interrogated by those educational researchers concerned with understanding the nature of policy enactment. The research findings we report in this paper are derived from a three year case study (Yin, 2009) utilising a classic grounded theory approach (Glaser and Strauss, 1967), undertaken in one Canadian secondary school as it 
sought to implement a new mathematics curriculum policy mandated by the provincial Ministry of Education.

The early work of Bowe and Ball (1992) and Ball (1993), used the concept of the policy cycle as a lens through which to examine the policy process. For Bowe and Ball (1992) the policy cycle operated within a triumvirate of contexts: the context of influence, representing the discoursesadvanced by various groups and stakeholders intent on inserting specific priorities into policy formation; the context of text production, where complex written texts of policy documents may be subject to interpretation and re-configuration in order to negotiate textual understanding; and the context of practice, where the prior knowledge, understanding, beliefs and experience of educational practitioners may frame and shape their interaction with the intended policy.

In subsequent research Braun et al (2010) elaborate the importance of the interactive nature of policy actors' influence in framing the outcome of policy processes. As they state:

....an examination of policy enactment at a school level is about examining connections and inter-dependencies. It is important to consider, firstly, that policies are processes, even when mandated, and policy texts can be differently worked on and with. Secondly, policy practices are specific and contextualised. They are framed by the ethos and history of each school and by the positioning and personalities of the key policy actors involved. And thirdly, and related to the contextualised aspect of practice, policies are mediated by positioned relationships: between government and each local authority, the local authority and each of its schools, and within, as well as between schools.

(Braun et al., 2010, p.558). 
The above exposition bears careful consideration as being foundational to developing a clearer understanding of the interpersonal dynamics of policy processes at a local level, where site based policy actors negotiate the constant stream of policy initiatives requiring their attention. An important idea emergent from this work is the notion that relationship dynamics between policy actors engaging with policy processes create shared understandings that act as lenses through which new policies are screened, filtered and dissected for meaning, resonance and relevance. They note that the implementation of the same policy in sites exhibiting different relationship dynamics may give rise to different perceptions, attitudes and degree of commitment to the policy, contextually bound to variations in factors such as clientele, staff and resources (Braun et al., 2010).

Braun et al (2011) elaborate further the ways in which policy actors are positioned in a professional context framed by their "values, commitments and experiences" (Braun et al 2011, p.591) that may determine the degree of individual and or group engagement and interaction with policy enactment. They suggest that "dissonances between embedded institutional values and national policy trends" (p.591) may give rise to site based tensions when policy processes are in conflict with the professional context of policy actors, thereby reframing the process of engagement and subsequent policy enactment.

Further, Maguire et al (2010) suggest that at particular sites, policy discourse embedded within institutional texts and artifacts, serve to advance a preferred vision of reality, privileging that vision to the detriment of others. In essence, discourse becomes the tool that conserves power and authority within policy processes. As policy actors are subjected to those discourses in their engagement with policy processes, it follows that the influence of those discourses may impact how they receive, construct and perceive policies in the course of their interactions. Ball et al (2011a) address this notion of discursive reflection in suggesting that 'teachers make meaning with the discursive possibilities available to them' 
(p.612) advancing the point that 'different ... kinds of policies, position and produce teachers as different kinds of policy subjects' (p.612). Ball et al (2011a) differentiate between 'imperative' and 'exhortative' (p.612) policies; wherein the former constrains and narrowly defines policy maneuverability and the latter delivers a degree of creative freedom for policy actors to 'bring judgment, originality and 'passion' ... to bear upon the policy process' (p.615).

Significantly, while Ball et al (2011a., 2011b., 2012) provide conceptually what can be taken as a seminal account of policy enactment, their work and that of subsequent authors (Singh et al., 2013, 2014; Tan, 2017; Vincent et al 2016) touch relatively lightly on what Ball et a (2012) almost in passing term 'affective and psychosocial dimensions' (p.147) in relation to policy enactment. In referring to the relationship they consider to exist between affective dimensions of emotional capital in schools and policy enactment, Ball et al (2012) state:

Often teachers (and other adults) work in a school (and stay working in it) because of friendships they have built, commitment to their colleagues and the energising ethos of the school. These affective dimensions can cushion the everyday school life and enable staff to weather the policy storm.....A school that can cultivate and draw on this kind of emotional capital will have a different capacity for policy enactment than an institution which does not inspire loyalty and commitment of its staff.

(Ball et al, 2012: 41).

For Ball et al (2012) the affective dimensions coalesce around school contextual factors not covered by what they term 'professional factors' (p.147) such as collegiality, institutional 
loyalty and 'commitment in its staff' (p.41) and a 'willingness to take on (and put up with) policies and frequent policy changes' (p.47).

In this sense the affective dimensions focus not upon the social actors' emotional response to the policy under enactment but rather the affective emotional associations between social actors within the school and the implications this has for policy enactment. Indeed Ball et al (2012) appear to be particularly critical of the work of Spillane (2004) whose research considers policy implementation (rather than enactment) as 'a complex cognitive process' (p.4), drawing on the notion of sense-making aligned to policy actor agency to help explain why or why not policies are implemented.

Spillane et al (2002) examining sense-making in relation to policy processes argue that the 'social, environmental and contextual dimensions of human cognition mediate the interpretation and understanding of policy intent. They contend policy messages are not inert, static ideas that are transmitted unaltered into local actors' minds to be accepted, rejected or modified to fit local needs and conditions. Rather, the agents must first notice, then frame, interpret, and construct meaning from policy messages' (Spillane et al 2002, p.392). In advancing their position, Spillane et al (2002) argue that affective traits such as values, emotions and motivations, are also important aspects contributing to the sense-making process. Subsequently, the degree to which these aspects mediate and impact sense-making influences the manner in which policy processes unfold. Spillane et al., (2002), articulate a position that calls for a move away from a purely behavioural focus in framing the actions of policy actors, towards developing an appreciation for how they "construct understandings of the policy message, construct an interpretation of their own practice in light of the message and draw conclusions about potential changes in their practice as a result" (Spillane et al., 2002, p.392). This argument thus locates sense-making by policy actors as central to policy 
engagement. For Ball et al (2012) their concern with Spillane's (2004) work resides with a number of issues.

Firstly, insufficient 'understanding how it is that certain policies or strands within policies become picked up and worked on why they are selected and who selects them and what alternatives are discarded along the way' ( $\mathrm{p} 4)$. Secondly, the school as the site of policy implementation is conceived by Spillane et al (2002) as a 'homogenous and decontextualized organisation' (p4), with insufficient acknowledgement to the different cultures, histories traditions and communities of practice that co-exist in schools 'nor the school buildings or the availability of resources (p5). In essence, according to Ball et al (2012), the 'emphasis on sensemaking literally de-materialises policy’ (p5).

In contrast more social psychologically focused research into policy work and sense-making, frames sense-making as a cognitive process (with recognizable structural elements) which does not occur in isolation but operates in concert with, and is impacted by, affective emotional components (Weick 2005, Bartunek 2006, Avey 2008). In Weick’s (2005) conceptual construction the 'interplay of action and interpretation rather than the influence of evaluation on choice' (p.409), shifts the sense-making construct away from a purely rational, cognitive process towards one that considers affect and emotions as dimensions of sensemaking that may act interpretively in framing a particular course of action. This proposition was previously recognized by Nias (1996) in suggesting that as 'emotions are rooted in cognition' individuals cannot 'separate feelings from perception, affectivity from judgement' and further that "neither cognition nor feeling can be separated from the social and cultural forces which help to form them and which are in turn shaped by them' (p.294). Nias (1996) thus recognizes that emotional responses are structurally embedded processes within policy actors that operate parallel to, and are reciprocally activated through, interactions with their cognitive apparatus. In essence, emotion and cognition, whilst being separate constructs, are 
inexorably linked. Consequently while sense-making itself may be a potentially important factor in shaping individual's response to policy enactment, there might also be a need to understand further the possible role of emotional disposition and affect in shaping policy actor response and behaviour.

The existing social psychological literature (Spillane 2002, Bartunek 2006, Avey 2008, Stensaker 2008) in acknowledging that the activation of the social cognition processes of sensemaking do not fully account for how individuals mediate an understanding of the process of change, advance the notion that affect and emotions may have a role in mediating individuals' behaviours during their negotiation of change processes. Moreover, the conceptual notion of core affect advanced by Russell (2003), as being systemically present and situationally fluid in terms of its activation levels in response to external conditions, raises additional questions on the possible impact of affect and emotions as mediating factors influencing the responses of individuals with change processes associated with policy enactment.

Framed primarily by the sociologically informed body of conceptual and seminal work on policy enactment (Ball et al 2012), the research reported in this paper sought to apply a classic grounded theory approach (Glaser and Straus, 1967) to policy enactment with the intent of ultimately enabling a core concept of understanding to emerge from the data. The single case study site chosen for the investigation was a Canadian Secondary school of 1300 students, 80 teachers and support staff, with a School Leadership Team (SLT) of three administrators. The School was mandated by the provincial government to implement a new mathematics curriculum policy within the School

\section{Methodology}


As stated, the research adopted a case study approach (Yin, 2009) and used classic grounded theory (Glaser and Strauss, 1967) for data analysis, applying rigorous research procedures leading to the emergence of conceptual categories and a core concept. The data reported here were predominantly derived from semi-structured interviews (Fontana \& Frey 1994). The interviews were undertaken as open ended conversations with considerable scope for interviewees and interviewers to pursue emerging lines of enquiry, focusing on the subject's engagement with and perceptions of curriculum implementation processes at the school level.

Twenty digitally recorded interviews of approximately one hour duration were conducted over the course of the study with thirteen interviewees with iterative cycles of data collection and data analysis applied in a manner consistent with classic grounded theory (Glaser and Strauss, 1967). The sample of twenty interviews was deemed to be consistent with Guest et al (2006) in examining non-probabilistic theoretical sampling size in relation to developing theoretical saturation as applied to a grounded theory investigation.

In accordance with classic grounded theory (Glaser and Strauss, 1967), informants were chosen in relation to their relevant knowledge of the processes being investigated and fit the criteria as qualified informants (Morse 1994) by virtue of their experience with the policy under enactment. Eleven of the interview subjects were teachers and two were members of the School Leadership Team (SLT). Following an initial data analysis phase additional interviews were conducted with seven of the original informants. The rationale and purpose of these further interviews was to enable a more in-depth analytical probing and testing of the emergent findings to take place. Data collection in this phase was seeking to 'draw down' on the knowledge, understanding and insight of key informants, in order to identify and examine 
any 'data gaps' in the analysis and to confirm or disconfirm the analysis to-date and that theoretical saturation had or had

not been achieved (Glaser \& Holton, 2004).

A primary researcher was embedded in the research site, to undertake the task of data collection with the notion of reflexivity (Hammersley, 2005) stringently applied to ensure the integrity of the research process. Subsequently, detailed and in-depth discussion and critical reflection was undertaken by both researchers concerning data analysis, with coding and concepts scrutinised and examined for consistency, discrepancy, alignment or dissonance.

This process whilst time consuming and challenging was not found to be problematic in terms of disagreement. Rather, the shared, engagement with the data arguably enabled a more rigorous analytical consideration of multiple propositions.

Interview transcripts were examined and coded through line-by-line 'open coding', creating 'tags or labels for assigning units of meaning ... to information compiled during a study' (Miles \& Huberman 1994 p 55). The focus here was not on the words themselves, rather it was on the meaning ascribed to the words and/or phrases by the code; the ability to conceptualize ideas from the codes dependent on the interpretive robustness of the codes in framing an understanding of the text being analyzed. Subsequently, an iterative process of grouping conceptually related codes into categories was undertaken, with a constant comparison of the text and newly emergent codes against categories undertaken, as a means of triangulation of the analysis (Glaser \& Strauss 1967, Glaser \& Holton 2004, Holton 2007).

Following the emergence of a core set of categories, the constant comparative process was further utilized to examine categories for emerging themes and the assigning of "theoretical codes' (Glaser \& Holton 2004, Holton 2007, Hernandez 2009) to groups of categories that 
were thematically related. Subsequently, individual codes were analytically narrowed into conceptual categories that broadly captured and meaningfully organized the codes at a theoretically abstract level of meaning. These theoretical codes were a key part of the analytical process in that their identification required looking beyond the emergence of categories and concepts, towards linking them into a framework that offered theoretical insight into the observed phenomenon.

Table 1 below identifies the emergent conceptual properties of each category theoretically derived from the analysis. These properties reflect thematic frameworks that were analytically drawn out and conceptually developed from the coding analysis.

\section{INSERT TABLE 1}

The eleven categories (Table 1) derived from the coding process were analyzed in terms of their conceptual context and significance. Graphical concept mapping was subsequently employed as an analytical tool to 'specify the bins that hold the discrete phenomena' (Miles \& Huberman, 1994 p.22) with the eleven categories (as represented numerically in Table 1) conceptually grouped and situated around two axes; site based/system based and positive/negative (see Figure 1).

\section{INSERT FIGURE 1}

These two axes were selected as being representative of the range of perceptions held by teachers with respect to the identified factors associated with the process of policy enactment. Site

(schools-based) factors were framed as relating to those aspects that were specific to the case study site and deemed to be within the domain of policy actors (teachers) at the site (schoolbased) level. System based factors were viewed as being externally located to the case 
study site and beyond the scope of site based policy actors. The positive/negative axis analytically situated for each category the internalized perceptions adopted by policy actors (teachers) arising from their engagement and interactions with the policy enactment process. A positive valence was ascribed to policy actor (teacher) engagements that were favourably perceived and a negative valence to those viewed as being unfavourable.

Each category was mapped within the defined axial boundaries of the concept map based on the emergent constructs and perceptions derived from coding. Categories that were proximally located were grouped within the axial boundaries and these groupings were analytically developed at a higher level of conceptual abstraction. Conceptual fluidity along the axial dimensions in terms of locating categories was accounted by the use of bidirectional vectors to indicate such fluidity.

Further analysis at a deeper level of conceptual abstraction grouped the ideas embedded within these categories to six distinct emergent concepts (represented in figure 1) indicative of teacher engagement with the policy enactment process: (1) Professional and Emotional Investment (PEI), (2) Decisional Legitimacy (DL), (3) Hierarchical Trust, (4) System Integrity and Viability, (5) De-professionalization (DP) and (6) Identity Safeguarding (IS). Subsequent, adherence to the constant comparative process and conceptual analysis led to the identification of a core concept 'relating to as many other categories and their properties as possible and accounting for a large portion of the variation in a pattern of behaviour' (Glaser \& Holton, 2004, p.15). We have termed this theoretical core concept Affective Disruption.

In the following section we consider in more detail each of these six emergent concepts, and the core concept of Affective Disruption. In conclusion, in light of our findings, we tentatively elaborate on the social psychologically driven affective and emotional dimensions informing teacher engagement with policy enactment. 


\section{Research Findings}

\section{Professional and Emotional Investment (PEI)}

Our findings suggested the teachers in the study to have a strong professional and emotional investment in the education system. Teachers expressed a strong connection to teaching and a high degree of professional passion and having a commitment 'to doing the best possible job'.

Their passion for teaching appeared to be guided and informed by not simply instructional practice based on sound pedagogy but caring for their job and in particular the students whom they taught. As one teacher remarked:

I don't like making these students...guinea pigs, and having a whole year go by just because - in the name of a new initiative, have them be the guinea pig, and if it fails, well, it just fails. I just want to make sure I give those students the best I can.

All the teachers interviewed suggested a commitment to student care that was anchored by an emotional investment in behaviours that promote and protect student well-being. Consequently, any aspects of policy enactment which appeared to challenge this principle were scrutinized in terms of its attention to student care. In essence, teachers revealed an emotional and professional investment towards their students; investments which mediated their engagement with policy enactment.

Conceptual mapping (figure 1) analytically presents PEI with a high positive valence and in combination with its position along the site based axis is conceptually located away from 
external influences and factors and positively proximal to teachers. PEI is thus situated as internal to teachers and is framed by their emotional and affective positions

\section{Decisional legitimacy (DL)}

The teachers in the study were found to interrogate the Decisional Legitimacy of policy enactment, at times viewing the proposed curriculum change through a lens of scepticism, questioning the professional authenticity and rationale of the curriculum changes in terms of meeting the academic needs of students. As the following quote reveals:

The curriculum, one of the math courses was for students planning to go to university. The other course was designed for technical types of students. However there are students that have such weak math skills the level of the new curriculum was still too difficult for them.. they're just being pushed along because there isn't any other course.

Teachers were found to view the proposed new policy on the curriculum as privileging certain groups over others and expressed an obligation to act as the policy 'conscience' and the gatekeepers for enactment to ensure equity of access. Malen (2006) underscores this point in observing that 'Policies embody values, theories of interventions and orientations to social and educational issues that may or may not conform to the ideas, interests, and ideals of the actors who were involved in their adoption' (p.87). This notion is succinctly captured by the observations of Ball et al (2012) who suggest that 'what we take to be policies are power relations, practices and subjectivities which articulate forms of learning and forms of behaviour' (p.140). These values, interventions and orientations represent embedded discourses (Maguire et al 2011) which are perceived as advancing the interests of the external forces that frame the policy and are scrutinized by teachers and questioned for legitimacy. 
As a result teachers didn't simply accept the mathematics policy to be enacted in the School at face value rather they were found to question and interrogate the policy through personally constructed notions of professional understanding and knowledge, reframing their actions and behaviour to challenge its legitimacy when there was a perceived misalignment.

Furthermore, they questioned the motivation and agenda of policymakers scrutinising the overtly stated policy intent and asking would this really work for the students in the school, as one teacher remarked:

I often wonder if the people at the top are doing it for the kids ... I think when you're in the trenches you think, 'Were they really thinking about the kids? Or, is this going to look good on paper? Or, is it what the business world wants. I'm not sure the main driving factor is always in the spirit of improvement so much as increased efficiencies in delivering education.

Teachers were found in the main to hold the position of the sanctity of the educational enterprise, wherein the prime focus should be on advancing needs of the learners. Teachers at the Secondary school constantly questioned the authenticity and legitimacy of the policy enactment process when the 'big' decisions controlling the content of the reform were perceived as being externally located and non-educationally based. This questioning of decisional legitimacy in terms of the inception of policy initiatives supports the ideas of Coburn (2006) and Honig (2006) suggesting a need to unpack and understand the idea of authenticity in relation to the policy process.

Conceptually mapped (see figure 1), DL is perceived by teachers in terms of negative valence and this, in combination with its location along the system based axis, serves to construct the 
concept externally to teachers in terms of their domain of influence. The conceptual construction of DL as suggested by the analysis leads teachers to exhibit scepticism regarding the policy process, which they perceive as being inauthentic and controlling.

\section{Hierarchical Trust (HT)}

This emergent concept suggests teachers were found to value hierarchical authority or leadership that demonstrated a coherence of vision which promoted ethical trust through credible action.

Teachers had an appreciation of the fact that initial policy decisions to change and implement the new mathematics curriculum had been taken at governmental level and should be perceived as top-down. Seemingly, related to notions of decisional legitimacy, there was a suspicion on behalf of teachers of the ethics framing government based leadership decisions on the new and a lack of trust in government based policy decisions without any school-based knowledge. This position was in contrast with leadership team decisions taken at school based level. Secondary teachers understood that while school-based leadership needed to conform to top-down policy prerequisites in terms of policy introduction and conformity, they trusted school-based leaders to engage them openly in the process of policy enactment. As one teacher commented 'So even if the idea or thought came from somewhere else, at least it starts growing down here, at this particular area, so that gets buy-in. That's where it needs to happen'. Moreover, teachers expected and found the school-based leadership team to present a transparent framework of operationalizing policy by means of collegiality, consensus and mutual trust. A member of the School Leadership Team expressed the approach in the following terms:

The new policy for me always means professional development it's about changing conversations to the collegial, so that it's embedded into the rhythm of the day in 
terms of how we're going to approach it... it's about the dialogue moving into practice. We're in a place where we have to create relationships if we're going to move forward, if we're going to turn policy into best practice

Zhu et al (2004) advance notions of conditional and unconditional trust, where the former is dependent on a negotiated framework of action and the latter on implicitly aligned values framing such action. According to Zhu et al (2004) this notion of trust is contingent on ethically situated leadership behaviours that are perceived to be in the best interest of those towards whom the actions are directed, that promote individual empowerment and that are authentic and transparent.

Conceptual mapping (figure 1) analytically locates this category within both internal and external conditions that impinge on teachers. At one end there is a negative valence associated with hierarchical authority that is distally located to teachers and system based. At the other end a positive valence is associated with site (school-based) based hierarchical authority that is situated proximally to teachers. This suggests that Hierarchical Trust is conceptually located along a continuum where site (school-based) based or system based leadership represent the defining factors.

\section{System Integrity and Viability (SIV)}

System Integrity and Viability relates to the perceived consistent cycles of policy change encountered by teachers and the potential for these cycles to undermine the integrity and perceived viability of an initiative, resulting in at best scepticism and at worst outright hostility.

Teachers at the school were found to be particularly sceptical towards what they considered to be the consistent and repetitive cycles of policy change. As the following quote indicates: 
The new math curriculum, I don't jump up and down too fast any more. I've seen the pendulum swing. I never thought I'd be one of those people who sat in the back and says; oh we've seen this before. But it's true. The longer I teach the more I see things cycle and recycle, come back in a different way. Is it really new? Or is it just repackaged sometimes? I guess I am more cynical about it.

In addition to questioning the need for of curriculum change, teachers exhibited a high degree of concern regarding the financial viability of implementing the new curriculum. In particular they questioned the degree to which additional monies would be forthcoming from the provincial government to adequately resource the proposed changes within the school. A viewpoint linked to the notion of material contexts (Braun et al 2011, Ball et al 2012) around resource allocations informing the sustainability of school-based policy change.

This concept is analytically located (see figure 1) entirely external to teachers, being system based with a high negative valence in terms of proximity, locating it at the distal extremities ofthe concept map beyond the immediate influence of school site -based policy processes

\section{De-professionalization (DP)}

Teachers expressed concerns that the mandated policy change to the mathematics curriculumwas symptomatic of wider policy infringements, which due to their prescriptive and directives driven nature, were eroding their capacity to act as autonomous professionals, and informing a process of de-professionalization. The imposed policy shift creating a perception of externally enforced policy adaptation and a constriction of professional practice. As one teacher observed:

Well, if I'm thinking about the maths curriculum ... it filters down to this level, to the teacher level, where we have to implement, put in place what the policies are in terms 
of the changes in the curriculum... that mandate that we have, it restricts, and there are certain parameters within which we have to work.

A consistent theme to emerge from the analysis was a feeling amongst teachers of the futility of opposing policy changes per se, resulting in their resigned compliance. This perception of futility was intensified by the belief that policy enactments were ultimately the creature of external system-based governmental policy actors beyond the realm of their influence. In essence, while it was acknowledged by teachers that they could participate directly in determining the operationalization of the new mathematics curriculum, they didn't have any control over the creation of the new policy nor the fact that it had to be adopted. The compulsory obligation to incorporate the new policy into their professional practice was discovered to create in them internalized feelings of powerlessness and an emotional unease and discomfort in relation to their professional well-being.

If I see yet another policy coming down which says 'we are now going to change this, and change this, change this', because they see it from a different perspective, my sense is more often than not the word 'good' or 'innovative' is attached to it, and the assumption is, just like those car advertisements, that makes it better. I don't think it makes it better. ... So, when a new policy comes along, whatever it might be, whatever it might be, I am somewhat anxious

Teachers at the school enjoyed their positions as educators with the autonomy to conduct their practice based on informed pedagogy and professional standards; an imposed policy shift such as the new mathematics curriculum has the potential to create a situation of forced adaptation, where practice is externally shaped and autonomy eroded. In the circumstances teachers were found to draw upon prior understanding and negative experience of previous 
policy changes to decode the potential impact of the current policy enactment (Spillane 2002).

This emotional disconnect seemingly acted to reinforce their feelings of being subject to intentional de-professionalization at both the system and site school-based levels. The conceptual map (figure 1) analytically positions de-professionalization mid-way on the system/site axis with a high negative valence suggesting that the construct may be located internally within teachers and is possibly independent of the source and origin of policy processes.

\section{Identity Safeguarding (IS)}

Related in part to the previous emergent concept, identity safeguarding speaks to the ways in which teachers in response to the policy enactment sought to find ways to safeguard their professional identity. As stated already, teachers were found to internalise the pressures placed on them by the policy enactment process as potential threats to their professionalism. As a consequence they were found to consciously engage in strategies intended to preserve their authority over their professional practice. In some cases this might mean avoiding the policy altogether as one teacher commented 'sliding right by it and continuing to do your own thing' or as another suggested more strategically 'we adapt the math curriculum, we change it a little bit, pad it, take out or teach less of some things we don't think are important'. Other teachers in response to enacting the new curriculum said they would 'go through the motions' and either limit what they did or do 'just enough to stay within the policy'. For some it was a case of waiting to see how much traction the new initiative might have as one teacher remarked 'I am keeping my head down and what happens, happens. Is it the flavour of the month, or is this going to be something that actually sticks?' The reaction of teachers in this way could be understood as activation of sense-making (Spillane 
2002); a lens through which individuals interpret and re-interpret the environment in which they operate. Spillane's (2002) notion suggests that individuals 'construct understandings of the policy message, construct an interpretation of their own practice in light of the message and draw conclusions about potential changes in their practice as a result' (Spillane, 2002 p.392).

Identity Safeguarding conceptually mapped exhibits a high positive valence but is neutral in terms of its positioning on the site/system axis, suggesting that it is similar in conceptual construction to the concept of de-professionalization, in terms of being internally located to teachers. The conceptual differences however lies in the notion that IS may be perceived as a positive affective response in terms of a being a vehicle whereby teachers preserve their professional identity through controlling the external factors that are negatively impacting upon them.

\section{Core Concept - Affective Disruption}

\section{INSERT FIGURE 2}

We define the identified core concept Affective Disruption as a disruption to the emotional equilibrium of teachers that arises due to interference to the cognitive process of sensemaking that teachers' access in negotiating their understanding of externally initiated structural change. In the proposed model (figure 2) Affective Disruption is triggered within teachers as a response to the tensions created by the opposing and competing internal and external forces associated with site school-based based policy enactment. The degree to which the emotional imbalance of

Affective Disruption is precipitated varies according to teachers' perceptions of the intensity of these opposing internal and external forces. Where policy enactment exacerbates the 
intensity between the forces of Professional and Emotional Investment/Deprofessionalization/Identity Safeguarding and the opposing forces of Hierarchical Trust/Decisional Legitimacy/System Integrity and Viability, emotional disruption to a cognitive negotiation of the change through sense-making arises.

This notion of an affective/emotional response builds on the notion of core affect advanced by

Russell (2003), elaborating the existence within individuals of an affective disposition in terms of their activation levels in response to pleasure or pain producing external stimuli. Affective Disruption is theoretically envisioned as being precipitated by the competing and opposing forces at play both internally and externally to individuals involved in ]the policy enactment processes. Internal forces are identified as acting in a manner that positively reinforces an individual's personal sphere of control over policy enactment, whereas with external forces such control is called into question.

In attempting to process this conflict through the cognitive lens of sense-making, individuals are seemingly faced with the dilemma of intellectually rationalizing policy processes so as to preserve those personal areas of control. However, when this cognitive framework of sensemaking fails to resolve the dilemma, emotional responses are activated within individuals that provide an alternate method of negotiating the conflict. This overarching emotional response is posited to be in the form of Affective Disruption, wherein an individual's emotional equilibrium becomes displaced, requiring a recalibration of the emotional and affective processes in order for equilibrium to be re-established. This formulation of Affective Disruption thus forces those individuals to re-establish equilibrium through either reassessing and reconfiguring their emotional framework in the light of externally formulated challenges, or reverting to an emotional mindset where those 
challenges may be discounted and disregarded. Affective Disruption thus forces individuals to recognize that their emotional responses in coping with the challenges of change are as critically important as their cognitive responses

\section{Towards a Policy Social Psychology}

In so far as the classic grounded theorising approach of our study highlighted the social psychologically informed notion of Affective Disruption as the core concept, we do not wish to underplay the extent to which policy enactment remains a highly contextualised, complex and fragmented process whereby policy may be challenged, nuanced, reformulated, and changed(Braun et al 2010). Braun et al (2010, p. 549) capture the 'creative processes' associated with policy enactment as one which involves 'interpretation and recontextualisation - that is, the translation through reading, writing and talking of text into action and the abstractions of policy ideas into contextualised practices'. The important premise underpinning this is that "policies do not normally tell you what to do, they create circumstances in which the range of options available in deciding what to do are narrowed or changed, or particular goals or outcomes are set' (Ball 1994, p.19). From this perspective those concerned with educational reform at the school-based site level such as teachers are positioned in policy terms as 'key actors, rather than merely as subjects in the policy process' (Braun et al., 2010; 549). Moreover, the school setting, the nature of the policy (enforced or voluntary), the policy topic, school rituals, teacher identity and biography, school ethos and culture, the values and commitments of a particular school leader or leadership teams, and the profile of a particular policy as well as its timing, may all contribute to the attitude, stance and engagement of teachers individually and collectively towards a particular policy in a school (Maquire et al 2015). As Maquire et al (2015) observe 
..enacting policy is a complicated and sometimes inchoate process. It is both contingent andspecific, situated in time/space and seen as less/more important by different policy actors in schools'

(Magure et al 2015, p.7).

Significantly, Maquire et al (2015) revisit and seemingly soften in their previous critique (Ball et

al. 2012) of the more social psychologically informed work of Spillane (2004) and the argument that teacher engagement with policy involves a process of sense-making; as policy actors 'use the lenses they have developed through experience to filter their awareness' (p. 7) and subsequently their position towards a particular policy. Maquire et al (2015) take up this important notion of sense-making to acknowledge in line with Haidt (2012) that teacher engagement might not simply or necessarily be rational but could be emotional; the emotional response of teachers to a policy impacting upon the process of enactment.

Our classic grounded theory approach appears to validate and support this point, uncovering and portraying the ways in which sense-making and emotional affect impact upon teacher engagement with the enactment of a mathematics curriculum policy into their school. In addition, the findings were found to be highly individualized, such that while teachers were found to express similar perspectives there was very little evidence in support of Braun et al. (2010) concerning collective or collegiate considerations towards policy enactment.

The more social psychologically informed literature (Spillane 2002, Bartunek 2006, Avey 2008 ,

Stensaker 2008) suggest that activation of the social cognition processes of sense-making does not fully account for how individuals mediate an understanding of the process of 
change. In this light Bartunek et al (2006) and Avey et al (2008) advance the idea that affect and emotions have a role in mediating individuals' behaviours during their negotiation of change processes.

Furthermore, the notion of core affect advanced by Russell (2003) as being systemically present and situationally fluid in terms of its activation levels in response to external conditions, and in line with our findings, lends additional conceptual support to the impact of affect and emotions as mediating factors influencing the responses of individuals during their interactions and engagement with change processes such as policy enactment. We contend that the notion of Affective Disruption offers an explanation of the manner in which affective emotional components impinge on teachers as 'policy actors' during their engagement and interactions with policy processes. In this respect, the construction of Affective Disruption as an emotion based response mechanism is theoretically located as operating parallel to, but separate and distinct from, the cognitively situated process of sense-making. Moreover, this formulation theoretically aligns with both the models advanced by Bartunek et al (2006) where sense-making and affect are viewed as distinct mediating variables governing individual engagement with the process of change, and that of Avey et al (2008) whereby emotion and affect are situated as factors mediating the emergence of positive or negative attitudes and behaviours in the process of negotiating change processes. Thus policy actors' interactions and engagement with policy processes are subjected to a range of forces that elicit Affective Disruption with respect to the internal impact of those forces. This emotion laden core presents implications for practice in terms of understanding and mediating the impact of Affective Disruption on the policy enactment process in certain key ways. First, enactment processes may need to give recognition and importance to the emergent affective responses that may impinge on policy enactment. Such recognition must take account of the differentiation in these responses along site based and system based lines, in order to better 
understand their potential impact on policy processes as they unfold. Second, policy processes may need to encompass structures that mitigate negative and advance positive affective responses towards policy enactment. In these terms, such structures must diminish and counteract the emergent emotional tensions between forces internal to and external to policy actors, that precipitates the conditions for Affective Disruption to be realized. Third, any such mediating structures may need to be aligned with the internal emotional and affective priorities of policy actors, as opposed to being perceived as negating those priorities. This alignment thus sharpens the focus of policy processes towards understanding the affective dimensions that influence policy actors as they negotiate the policy landscape. Finally, increased prominence may need to be given to the emotional affective dimension impacting policy processes, separate and apart from sole considerations of the cognitive dimensions. Policy processes are dependent on human interactions and engagement in terms of their efficacy. Failure to pay attention to this affective dimension, which has embedded within it an emotional framework, is a potential failure to recognize the indispensability of the human dimension to policy processes.

In identifying the six emergent concepts indicative of teacher / policy actor engagement with the policy process namely Professional and Emotional Investment, Decisional Legitimacy, Hierarchical Trust, System Integrity and Viability, De-professionalization and Identity Safeguarding and the core concept of Affective Disruption, we hope to have contributed toward what might embryonically and tentatively be termed a policy social psychology. Our social psychologically informed findings on the affective and the emotional augmenting previous moresociologically grounded seminal work on policy and policy enactment (Bow and Ball, 1992; Ball, 1993; Braun et al., 2010; Ball et al 2012)

\section{References.}


Avey, J. B., Tara S. Wernsing, Fred Luthans (2008). 'Can Positive Employees Help

Organizational Change? Impact of Psychological Capital and Emotions on Relevant Attitudes and Behaviours.' Journal of Applied Behavioural Science 44(1): pp. 48-70.

Ball, S. J. (1993). 'What Is Policy? Texts, Trajectories and Toolboxes.' Discourse 13(2): pp. $10-$

Ball, S. J., Maguire, Meg., Braun, Annette., Hoskins, Kate. (2011a). 'Policy Subjects and Policy

Actors in Schools: Some Necessary but Insufficient Analyses.' Discourse: Studies in the Cultural Politics of Education 32(4): pp. 611-624.

Ball, S. J., Maguire, Meg., Braun, Annette., Hoskins, Kate. (2011b). 'Policy Actors: Doing Policy Work in Schools.' Discourse: Studies in the Cultural Politics of Education 32(4): pp. 625-639.

Ball, S. J., Maguire, Meg., Braun, Annette. (2012). How Schools Do Policy: Policy Enactments in Secondary Schools. London, Routledge.

Bartunek, J. M., Denise M. Rousseau, Jenny W. Rudolph, Judith A. DePalma (2006). 'On the Receiving End: Sense-making, Emotion, and Assessments of an Organizational Change Initiated

by Others.' Journal of Applied Behavioural Science 42(2): pp. 182-206.

Braun, A., Meg Maguire, Stephen J. Ball (2010). 'Policy Enactments in the UK Secondary School: examining policy, practice and school positioning.' Journal of Education Policy 25(4): 
pp. 547-560.

Braun, A., Ball, Stephen J., Maguire, Meg., Hoskins, Kate. (2011). 'Taking Context Seriously:

Towards Explaining Policy Enactments in the Secondary School.' Discourse: Studies in the Cultural Politics of Education 32(4): pp. 585-596.17.

Case, R. (1994). 'Our Crude Handling of Educational Reforms: The Case of Curricular Integration.' Canadian Journal of Education 19(1): pp. 80-93.

Coburn, C. (2006). 'Framing the Problem of Reading Instruction: Using Frame Analysis to Uncover the Microprocesses of Policy Implementation.' American Educational Research Journal 43(3): pp. 343-279.

Creswell, J. W., Miller, Dana L. (2000). 'Determining Validity in Qualitative Inquiry.' Theory into Practice 39(3): pp. 124-130.

Darling-Hammond, L. (1990). 'Instructional Policy into Practice: 'The Power of the Bottom over

the Top'. Educational Evaluation and Policy Analysis 12(3): pp. 339-347.

Glaser, B., Strauss, Anselm (1967). The Discovery of Grounded Theory Chicago, Aldine.

Glaser, B., Strauss, Anselm (1967). The Discovery of Grounded Theory: Strategies for Qualitative Research. Chicago, Aldine. 
Glaser, B. G. (2002). 'Conceptualization: On Theory and Theorizing Using Grounded Theory'

International Journal of Qualitative Methods 1(2): pp. 1-31.

Glaser, B. G., Holton, Judith (2004). 'Remodeling Grounded Theory.' Forum: Qualitative Social

Research 5(2): Art. 4.

Hammersley, M., Atkinson, Paul. (2007a). Ethnography: Principles in Practice. London, Routledge.

Hargreaves, A. (2001). 'Emotional Geographies of Teaching.' The Teachers College Record 103(6): pp. 1056-1080.

Hargreaves, A. (2004). 'Inclusive and Exclusive Educational Change: Emotional Responses of

Teachers and Implications for Leadership.' School Leadership \& Management 24(3): pp. 287309.

Hargreaves, A. (2005). 'Educational Change Takes Ages: Life, Career and Generational Factors

in Teachers' Emotional Responses to Educational Change.' Teaching and Teacher Education 21(8): pp. 967-983.

Honig, M. I. (2006). Complexity and Policy Implementation. New Directions in Education 
Policy Implementation. M. I. Honig. Albany, SUNY Press: pp. 1-23.

Huberman, M. (1989). 'The Professional Life Cycle of Teachers.' The Teachers College Record

91(1): pp. 31-57.

Johnson, C. E., Shelton, Paul M. (2012). 'Nice Guys (and Gals) Finish First: Ethical

Leadership

and Organizational Trust, Satisfaction, and Effectiveness.' International Leadership Journal 4(1): pp. 3-19.

Kelchtermans, G. (2005). 'Teachers' Emotions in Educational Reforms: Self-Understanding, Vulnerable Commitment and Micropolitical Literacy.' Teaching and Teacher Education 21(8):

pp.995-1006.

Louis, M. R. (1980). 'Surprise and Sense Making: What Newcomers Experience in Entering Unfamiliar Organizational Settings.' Administrative Science Quarterly 25(2): pp. 226-251.

Maguire, M, Braun, Annette., Ball, Stephen J. (2015) 'Where you stand depends on where you sit': the social construction of policy enactments in the (English) secondary school, Discourse: Studies in the Cultural Politics of Education, 36(4); pp. 485499

Maskit, D. (2011). 'Teachers Attitudes Toward Pedagogical Changes During Various Stages of 
Professional Development.' Teaching and Teacher Education 27(5): pp. 851-860.

Miles, M. B., A. Michael Huberman (1994). An Expanded Sourcebook Qualitative Data

Analysis. Thousand Oaks, CA, Sage.

Nias, J. (1996). 'Thinking About Feeling: The Emotions in Teaching.' Cambridge Journal of

Education 26(3): pp. 293-306.

Palanski, M. E., Yammarino, Francis J. (2009). 'Integrity and leadership: A multi-level conceptual framework.' The Leadership Quarterly 20(3): pp. 405-420.

Russell, J. A., Barrett, Lisa Feldman (1999). 'Core Affect, Prototypical Emotional Episodes, and

Other Things Called Emotion: Dissecting the Elephant.' Journal of personality and social psychology 76(5): pp. 805-819.

Russell, J. A. (2003). 'Core Affect and the Psychological Construction of Emotion.'

Psychological Review 110(1): pp.145-172.

Schmidt, M., Datnow, Amanda (2005). 'Teachers' Sense-Making about Comprehensive School

Reform: The Influence of Emotions.' Teaching and Teacher Education 21(8): pp. 949-965.

Singh, P., Heimans Stephen \& Glasswell Kathryn (2014). 'Policy enactment, context and performativity: ontological politics and researching Australian National Partnership policies.' Journal of Education Policy, 29:6, 826-844 
Singh P., Thomas, Sue \& Harris, Jessica (2013) 'Recontextualising policy discourses: a Bernsteinian perspective on policy interpretation, translation, enactment.' Journal of Education

Policy, 28:4, 465-480

Spillane, J. P., Reiser, Brian J., Reimer, Todd (2002). 'Policy Implementation and Cognition:

Reframing and Refocusing Implementation Research.' Review of Educational Research 72(3):

pp. $387-431$.

Steffy, B. E., Wolfe, Michael P. (2001). 'A Life-Cycle Model for Career Teachers.' Kappa Delta

Pi Record 38(1): pp. 16-19.

Stensaker, I., Falkenberg, Joyce., Gronhaug, Kjell (2008). 'Implementation Activities and Organizational Sense-making.' Journal of Applied Behavioral Science 44(2): pp. 162-185. Tan, C (2017). 'The enactment of the policy initiative for critical thinking in Singapore schools.' Journal of Education Policy. DOI: 10.1080/02680939.2017.1305452 van Veen, K., Sleegers, Peter., Van de Ven, Piet-Hein (2005). 'One Teacher's Identity, Emotions, and Commitment to Change: A Case Study into the Cognitive-Affective Processes of a Secondary School Teacher in the Context of Reforms.' Teaching and Teacher Education 21(8): 
917-934.

Vincent, C., Neal, Sarah \& Humera Iqbal (2016) ‘Children’s friendships in diverse primary schools: teachers and the processes of policy enactment.' Journal of Education Policy, 31:4, $482-$

494,

Weick, K. E. (1995). Sense-making in Organizations. Thousand Oaks, CA, Sage.

Weick, K. E. (2005). 'Organizing and the Process of Sense-making.' Organization Science 16(4): pp. 409-421.

Yin, R.K (2009) Case Study Research Design and Methods. Thousands Oaks, CA. Sage Zhu, W., May, Douglas R., Avolio, Bruce J. (2004). 'The Impact of Ethical Leadership Behavior on Employee Outcomes: The Roles of Psychological Empowerment and Authenticity.' Journal of Leadership and Organizational Studies 11(1): pp. 16-26. 

Table 1. Emergent Properties of Categories

\begin{tabular}{|c|c|}
\hline Category & Emergent Properties of Each Category \\
\hline 1. Professionally $\&$ Vocationally Vested & $\begin{array}{l}\text { Reflects professional competence, commitment to sound educational } \\
\text { practice and degree of career continuity of those engaging in policy } \\
\text { processes }\end{array}$ \\
\hline 2. Emotional Investment & $\begin{array}{l}\text { Reflects degree of dedicated commitment, recognition of personal } \\
\text { responsibilities and passionate engagement with learners }\end{array}$ \\
\hline 3. Locus of Control & $\begin{array}{l}\text { Reflects feelings of powerlessness resulting from external impositions, } \\
\text { creating an internal disequilibrium and imbalance in the ability to shape } \\
\text { their own environment }\end{array}$ \\
\hline 4. System Integrity \& Viability & $\begin{array}{l}\text { Reflects perceptions of inefficiencies and inadequacies in resource } \\
\text { allocation to support sound educational structures, threatening system } \\
\text { sustainability }\end{array}$ \\
\hline 5. Alienation & $\begin{array}{l}\text { Reflects levels of detachment, disconnectedness and marginalization of } \\
\text { those engaged in policy processes }\end{array}$ \\
\hline 6. Retrenchment & $\begin{array}{l}\text { Reflects strategic coping mechanisms engaged to manoeuvre through } \\
\text { contested policy processes }\end{array}$ \\
\hline 7. Policy Legitimacy & Reflects perceptions of authenticity, coherence and relevance \\
\hline 8. Collegially Connected & $\begin{array}{l}\text { Reflects formation of supportive and interdependent professional } \\
\text { networks to sustain professional capacity }\end{array}$ \\
\hline 9. Ideological Repurposing & $\begin{array}{l}\text { Reflects external drivers framing and delivering policy processes to fulfill } \\
\text { discrete and purposeful intent }\end{array}$ \\
\hline 10. Social Inequity & $\begin{array}{l}\text { Reflects capacity to leverage cultural capital in shaping preferred } \\
\text { educational outcomes }\end{array}$ \\
\hline 11. Ethical Trust & $\begin{array}{l}\text { Reflects level of confidence in leadership based on credibility of purpose, } \\
\text { ethical history and personal qualities }\end{array}$ \\
\hline
\end{tabular}




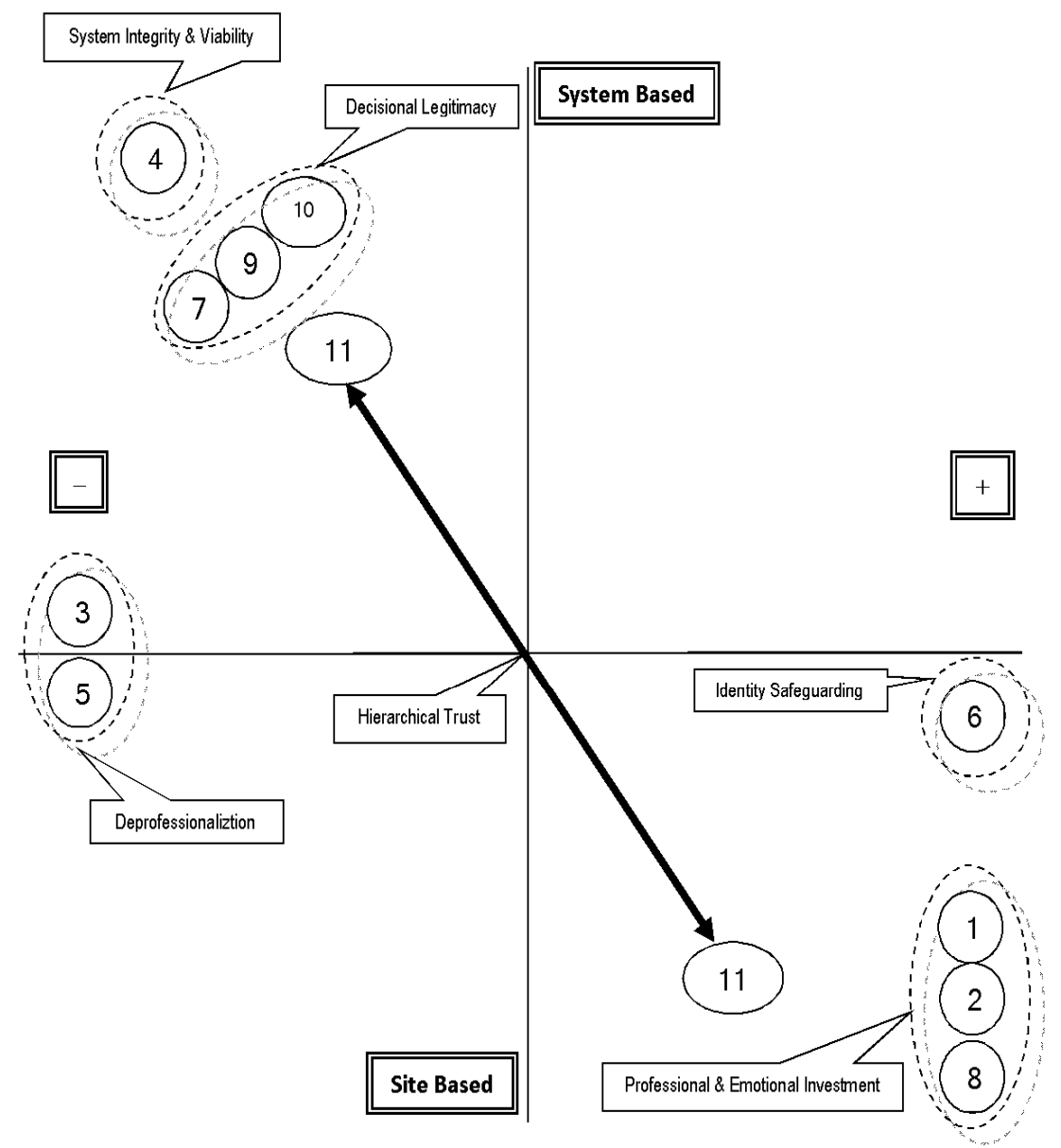

Figure1. Conceptually Mapping the Emergent Categories 


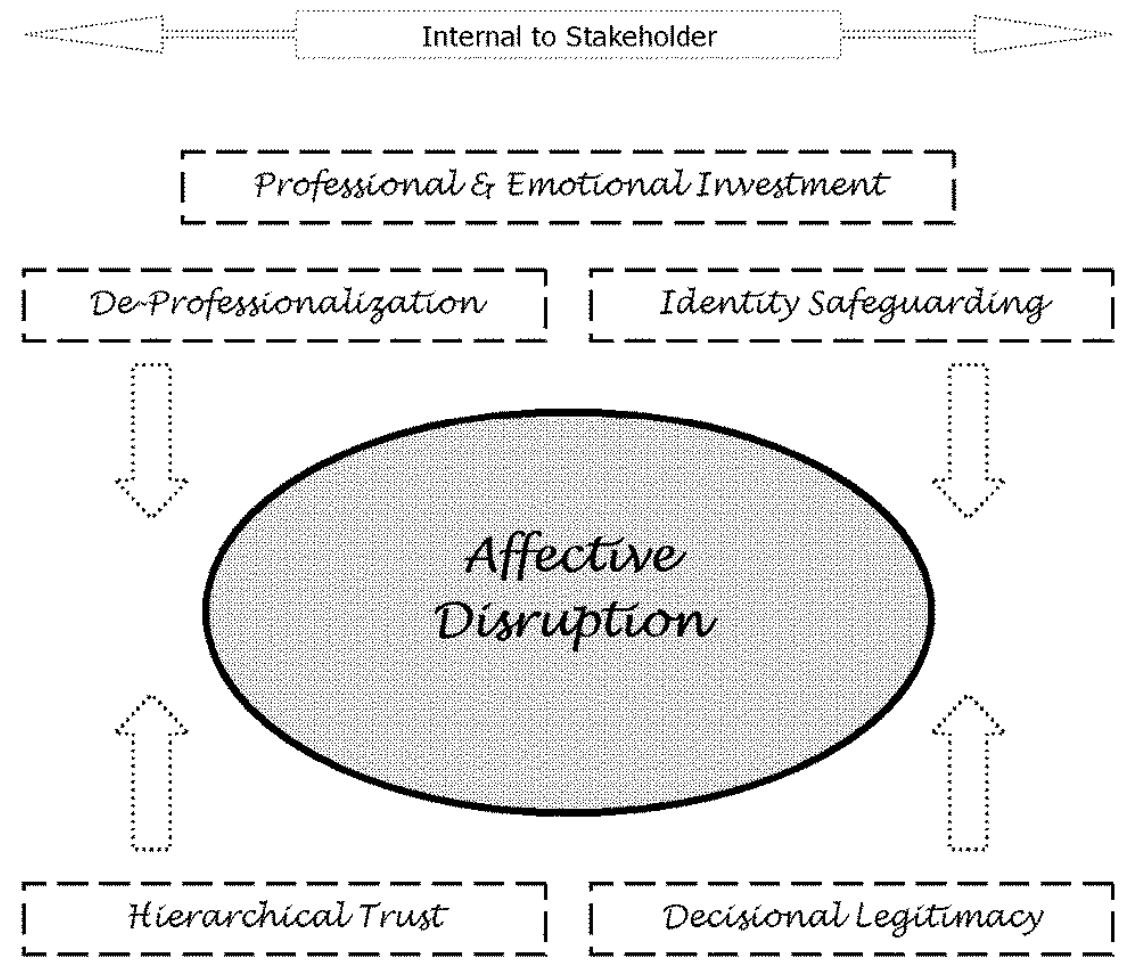

System Integrity E Viability

External to Stakeholder

